Supplement of Biogeosciences, 18, 4705-4715, 2021 https://doi.org/10.5194/bg-18-4705-2021-supplement (C) Author(s) 2021. CC BY 4.0 License.

(c) (i)

Supplement of

\title{
Diel patterns in stream nitrate concentration produced by in-stream processes
}

Jan Greiwe et al.

Correspondence to: Jan Greiwe (jan.greiwe@ hydrology.uni-freiburg.de)

The copyright of individual parts of the supplement might differ from the article licence. 

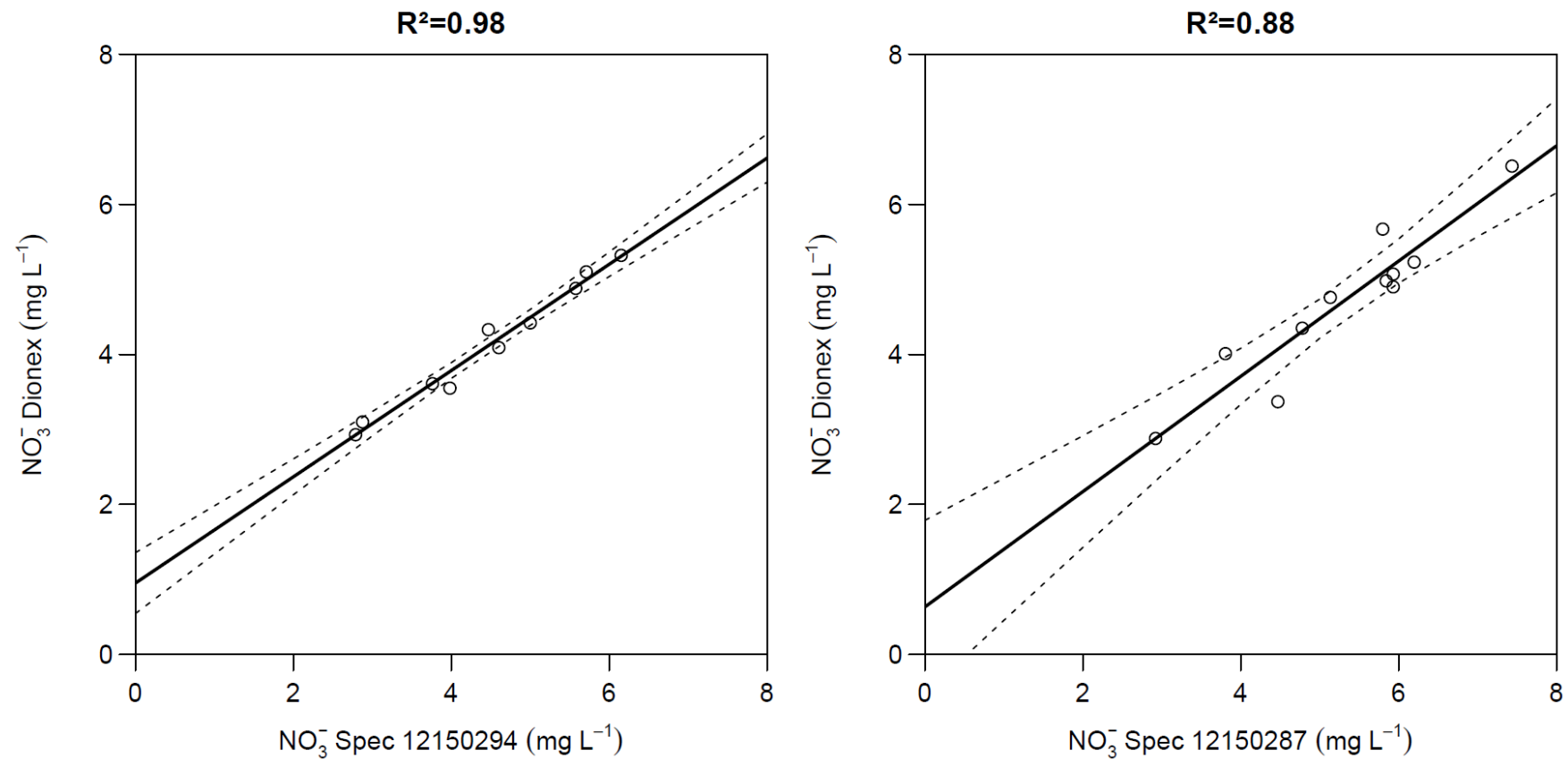

Figure S1: Local calibration of spectro::lyser probes obtained by comparing probe measurements any manually collected samples analysed using ion chromatography (Dionex ICS-1100). Dashed lines show $95 \%$ confidence intervals. 


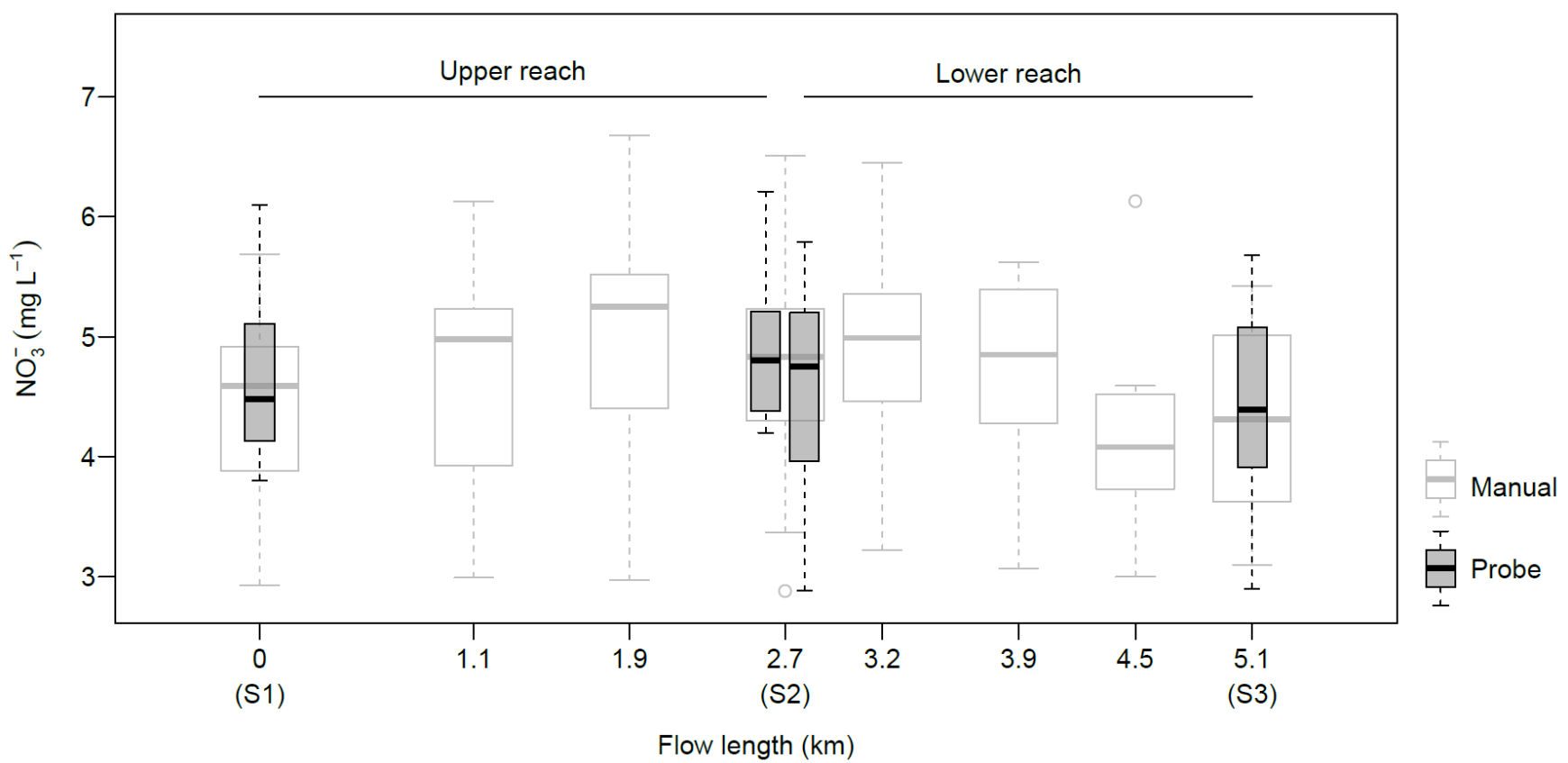

Figure S2: Distribution of daily means of probe measurements at monitoring sites and concentrations obtained from manual sampling at additional sites along the study reach. Probe measurements are displayed separately for periods where probes were placed in the upper or lower reach. 


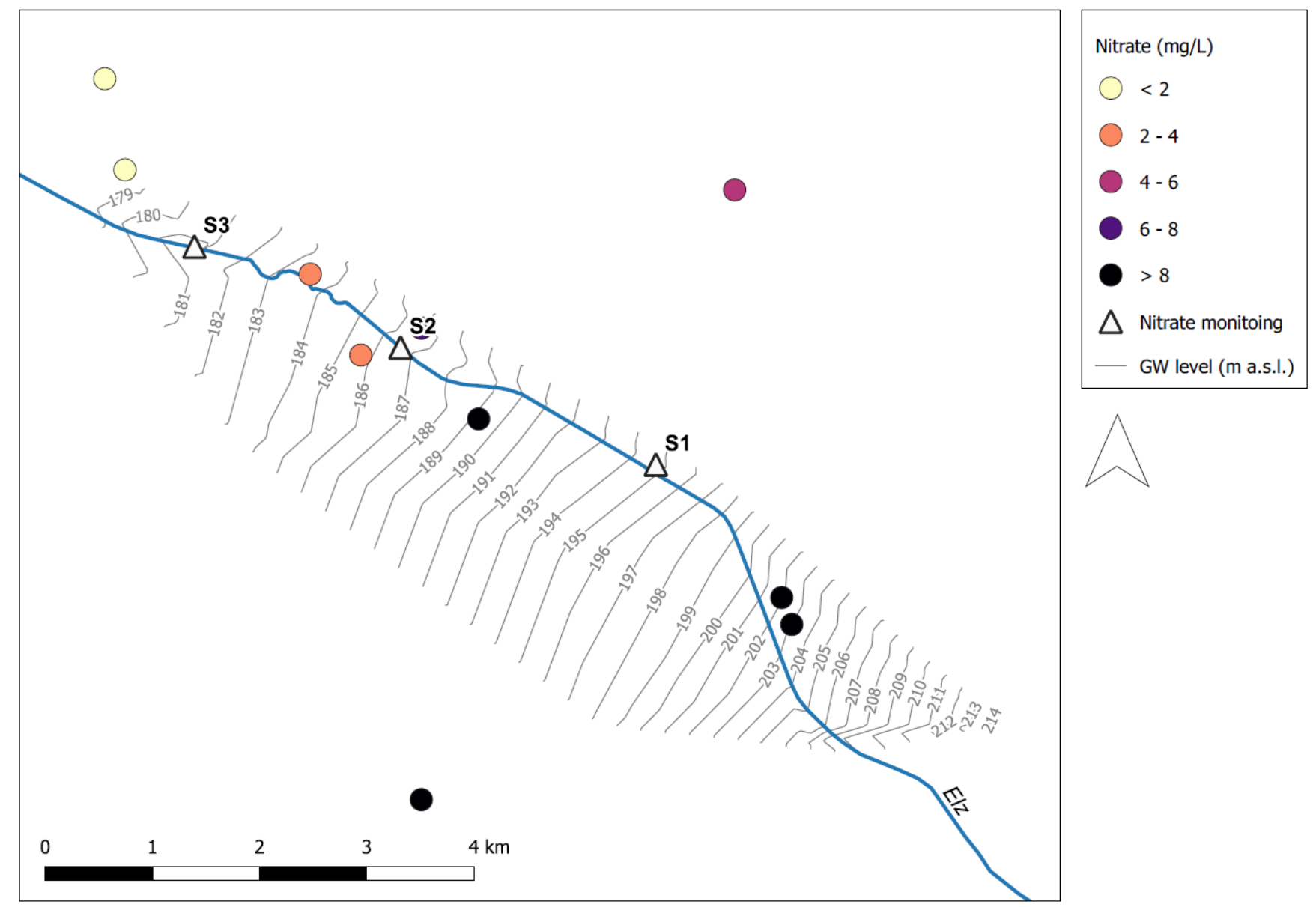

Figure S3: Groundwater head and $\mathrm{NO}_{3}{ }^{-}$concentrations in nearby groundwater wells. Groundwater data are publicly available from the State Office for Environmental Protection in Baden-Württemberg (www.lubw.baden-wuerttemberg.de). 